\title{
Physical model of the economic development
}

\author{
S.M. Yusifov, Economist \\ Baku city, Azerbaijan Republic
}

Aim: The aim is to build the physical model of economic development for preventing of an economic decline and achieve in economic development by saving the financial means allocated for economic development by selecting an alternative variant.

Keywords: economic development, physical model, economic decline, inflation, coefficient of physical activeness, the speed of light, kinetic energy.

Introduction: The main motive force of economic development basing upon modern technology is human capital [1]. The human capital is the costs spent on increasing of the working condition and welfare of the people. The amount of the financial means allocated for economic development has been increasing recently. The increase of the amount of money causes inflation to happen and it makes the working condition and living standards difficult and as a result, an economic decline happens. Naturally, it is necessary to save the allocated financial means correctly for not allowing such economic and social problems to appear. It is a necessary condition for selecting an alternative variant for the same reason. Therefore, it is an actual issue to build the physical mode of economic development by giving a physical meaning to the financial means saved by basing upon the alternative variant selected.

Description of the problem: Kinetic energy appears as a result of the movement of the body [2]. Money is a body in itself and has certain mass. As the circulation of the cashless money allocated for economic development basing upon modern technology is analogous to the movement of a body, let's us build the physical mode of economic development by admitting that the kinetic energy is formed from the same circulation.

Solution of the problem: The cashless money means allocated for economic development is distributed by transfer. As money transfers are realized by modern technologies, we can take the movement speed of the money (body) as equal to the speed of light $\left(3 \cdot 10^{8} \mathrm{~m} / \mathrm{sec}\right)$. Because the information is transmitted by the electromagnetic waves on the internet and the speed of spreading of the same waves is equal to the light speed of the money. Then, the kinetic energy of the money (body) with the mass $m$ will be $E_{k i n}=m c^{2}$. Here $m$ is the mass of money (body) and $c$ is the light speed. And now, let's define the mass of the money (body). For the same reason, let's assume that the money allocated for economic development conforms to the international paper monetary unit and its amount is $\mathrm{M}$. It is clear:

1) That the weight of 1.000 .000 Euros in the paper monetary unit with the nominal value of 100 Euros is $10.2 \mathrm{~kg}$; 
2) The weight of 1.000 .000 USD in the paper monetary unit with the nominal value of 100 USD is 10 $\mathrm{kg}$ and so on.

If we generally mark the weight of 1.000 .000 USD in the paper money of 100 with $P$, then the weight of the paper money of mass M will be $m=\frac{1 \mathrm{MxpP}}{1.000 .000}$

The kinetic energy created by the money with the mass $m$ will be $E_{k i n}=\frac{M * P}{1.000 .000} * c^{2}$

For example: the weight of 5.140.000 USD allocated for economic development will be $m=\frac{\text { MNXP }}{1.000 .000}=$ $=51,4 \mathrm{~kg} \cdot 3 \cdot 10^{8} \mathrm{~m}^{2} / \mathrm{sec}^{2}=1,542 \cdot 10^{10}\left(\mathrm{~kg} \cdot \mathrm{m}^{2}\right) / \mathrm{sec}^{2}=1542 \cdot 10^{10}$ joule.

We should note that if $\mathrm{M}$ - amount of the money allocated is not fully expressed with the international paper monetary unit of 100 , we may round off $\mathrm{M}$ number for defining of the weight of the monetary aggregates exactly. Thus, the total work done by the paper money (body) of mass $\mathrm{M}$ with kinetic energy Ekin will be counted by the formula of $\mathrm{W}_{\text {int }}=\mathrm{Ekin}=$ $\frac{\mathrm{M} * \mathrm{P}}{1.000 .000} * \mathrm{C}^{2}$

And now, let's justify the possibility of performing of the work to be done by the money of mass $\mathrm{M}$ with less money means by selecting an alternative variant. Supposing that it is possible to perform the work considered in the plan of economic development with the money means of mass $M_{1}\left(m_{1}<m\right)$. Let's mark the amount of the money of mass $m_{1}$ with $M_{1}$. Then the efficient kinetic energy of the money of mass $M_{1}$ will be $E_{\text {kin } 1}=m_{1} c^{2}$ but the efficient work $W_{\text {out }}=$ $\frac{\mathrm{M}_{1} * \mathrm{P}}{1.000 .000} * \mathrm{C}^{2}$

and here it was considered to be $m_{1}=\frac{M_{1} * P}{1.000 .000}$. The money means of mass $m$ or $m_{1}$ allocated for different fields planned for economic development is the result of the mental activity of the people with different professions. The allocation of the money means of mass $\mathrm{m}_{1}$ may be possible as a result of using of the knowledge and skills of the same people more efficiently and this time, the performed work is considered to be efficient. According to the calculations of the World Health Organization, the comparison of the total work performed by the people engaged in the mental activity with the efficient work is a stable number and equal to 1,4 [3]. This number is called the coefficient of physical activeness. By using this coefficient for planning of the economic development, that is, we can find $M_{1}$ amount of the money of mass $m_{1}$ from the correlation of $W_{\text {int }} / W_{\text {out }}=1,4$ and count the money means allocated for the efficient work. That is:

We get $\frac{W_{\text {int }}}{W_{\text {out }}}=\frac{M * P * c^{2}}{1.000 .000} / \frac{M_{1} * P * c^{2}}{1.000 .000}=M / M_{1}=1,4$. And from here, we will find that the 
amount of the money allocated for an alternative variant is $M_{1}=M / 1,4$.

For example: Supposing that the means in the amount of $M=6.145 .000$ USD were allocated for economic development. The money means allocated for the alternative variant will be $\mathrm{M}_{1}=$ $M / 1.4=6.145 .000 / 1.4=4.389 .285,7$ USD or $M_{1}=4.389 .300$ USD if we round off them.

Similarly, we will find out that the $\mathrm{m}_{1}$-weight of the money in the amount of $\mathrm{M}_{1}$ is $\mathrm{m}_{1}=\frac{\mathrm{M}_{1} * \mathrm{P}}{1.000 .000}$ . $=(4.389 .300 \cdot 10) / 1.000 .000=43,893 \mathrm{~kg}$.

We can similarly calculate the kinetic energy of the saved money in the amount of $\Delta M=M-M_{1}$ and the work it will do. That is, if we consider that the kinetic energy of the money in the amount of $\Delta \mathrm{M}$ :

$$
\begin{aligned}
& \Delta \mathrm{E}=\mathrm{E}_{\text {kin }}-\mathrm{E}_{\mathrm{kin} 1}=\mathrm{mc}^{2}-\mathrm{m}_{1} \mathrm{c}^{2}=\left(\mathrm{m}-\mathrm{m}_{1}\right) \mathrm{c}^{2} \text { but the work it will do is } \\
& \Delta W=W_{\text {int }}-W_{\text {out }}=\frac{\mathrm{M} * \mathrm{P} * \mathrm{c}^{2}}{1.000 .000}-\frac{\mathrm{M}_{1} * \mathrm{P} * \mathrm{c}^{2}}{1.000 .000}=\left(\frac{\mathrm{P}_{1.000 .000}^{2}}{1.000} /\left(\mathrm{M}-\mathrm{M}_{1}\right)\right. \\
& \text { )or } \mathrm{M}_{1}=\mathrm{M} / 1.4 \text {, then we }
\end{aligned}
$$
will get $\Delta \mathrm{W}=\left(\mathrm{M} \cdot \mathrm{P} \cdot \mathrm{c}^{2}\right) / 3.500 .000$.

Result: By considering the possibility of realizing of the cashless money transfers via internet in the civil societies or countries with high technologies, spreading of information with electromagnetic waves, in other words, at the light speed on Internet and taking of the paper money as the body which is its mass:

1) The paper money of mass $m$ in the amount of $m$ has kinetic energy;

2) The paper money of mass $m_{1}$ does work in the circulation and it is possible to count the amount of the same work;

3) We can realize the work done by the money of mass $m$ with less money of mass $m_{1}\left(m_{1}<m\right)$ and define the amount of the same money by considering the possibility of the alternative variant and thus, we can prevent the inflation. The solution of these problems is found by giving economic meaning to the coefficient of physical activeness.

\section{REFERENCES}

1. The physics of energy. Robert L. Jaffe, Washington, Taylor Cambridge University press 25.01.2018, page 894

\section{Principles of ECONOMICS, Third Edition Copyright@2004, N. Gregory Mankiw, Harvard University, Thomson /South-Western.}


3. Нормальная физиология учебник для медицинских вузов . К. В. Судаков, Медицинское информационное агентство, Москва 2006. - 918 с 